\title{
Change of Helicobacter pylori prevalence in a decade among children undergoing endoscopy
}

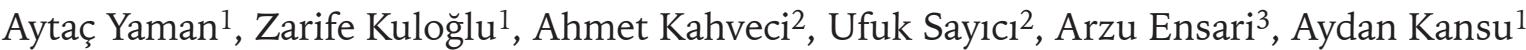 \\ Ankara University Faculy of Medicine, ${ }^{1}$ Pediatric Gastroenterology, ${ }^{2}$ Department of Pediatrics, ${ }^{3}$ Deparment of Pathology, \\ Ankara, Turkey. E-mail: aytacyaman@gmail.com \\ Received: 12th October 2016, Revised: 3rd January 2017, Accepted: 9th March 2017
}

\begin{abstract}
SUMMARY: Yaman A, Kuloğlu Z, Kahveci A, Sayıcı A, Ensari A, Kansu A. Change of Helicobacter pylori prevalence in a decade among children undergoing endoscopy. Turk J Pediatr 2016; 58: 579-582.
\end{abstract}

Our aim was to investigate the trend of $H$. pylori infection among children during the last decade by a retrospective analysis. Reports of children in whom esophago-gastroduodenoscopy was performed at our institution during two periods 2002-2003 and 2012-2013 were seperated into Group I and Group II, respectively. Pathology reports were investigated for gastritis, atrophy and H. pylori presence.

A total of 380 children, 131 in Group I and 249 in Goup II were recruited in the study. H. pylori postivity was found to be higher in Group I (\% 48.1 and $\%$ 23.1, respectively, $\mathrm{p}<0.001)$. Gastritis and atrophy were associated with H. pylori and both were more prevalent in Group I $(\mathrm{p}<0.001)$. Our study demonstrates that $H$. pylori prevalence is decreasing in a pediatric population undergoing EGD in Ankara. This is the most recent study regarding pediatric $H$. pylori prevalence change in Turkey that we know of.

Key words: H. pylori prevalence, children, endoscopy.

Helicobacter pylori infection is still one of the most common human infections. It is estimated that by mid adulthood $40 \%-80 \%$ of the population is infected worldwide where the prevalence in developing countries tends to be higher ${ }^{1}$. Prevalence exceeding $85 \%$ may be seen among young adult populations living in underdeveloped countries ${ }^{2}$. In a recent nationwide epidemiological study in Turkey among adults, $H$. pylori prevalence was $82.5 \%{ }^{3}$. Most recent $H$. pylori prevalence study involving Turkish children have reported a prevalence of $49 \%{ }^{4}$.

Decrease in H. Pylori prevelance over decades is a uniform finding worldwide ${ }^{5-8}$. Two European studies from The Netherlands and Finland found $H$. pylori prevalence decreasing from $50 \%$ to $20 \%$ and $31 \%$, respectively. Less developed countries like Greece and Estonia also experienced decreasing $H$. pylori prevalence in both adults and children. Literature studying trends of $H$. pylori prevalence in Turkey is scarce; only one study was found exploring the change of $H$. pylori prevalence in Turkey.
The study was conducted in 1990 and 2000 among children aged 7-149. The prevalence decreased from $78.5 \%$ to $66.3 \%$ but using serum based serology as the method of $H$. pylori detection rendered the results somewhat unreliable because of differing sensitivites and persistence of antibodies in serum long after the dissolution of infection ${ }^{10}$.

The aim of our study was to evaluate the prevalence change of $H$. Pylori infection, gastritis and gastric atrophy in children undergoing esophagogastroduodenoscopy (EGD) in Ankara within a 10- year period.

\section{Material and Methods}

This is a retrospective study which reviews the records of all EGD performed at the Pediatric Gastroenterology Division, Ankara University, Ankara, Turkey during two periods (January 2002-December 2003 and January 2012-December 2013), ten years apart. Children who underwent EGD during the period of January 2002-December 2003 were defined as Group I, whereas children who underwent EGD 
during the period of January 2012-December 2013 were defined as Group II.

A total of 590 children, 294 children in Group I and 296 children in Group II underwent EGDs during study periods. Gastric biopsies were available in 131 (44.6\%) and 249 (84.1\%) EGDs in Group I in Group II, respectively. Finally a total of 380 patients, $66.6 \%$ girls were enrolled in the study. The mean age was $12.3 \pm 4.7$ years.

Endoscopies were performed by two pediatric gastroenterologists and fellows under sedation. At least two biopsy specimens were obtained each from gastric antrum and corpus (body). Gastric biopsies were submitted for histology, stained with hematoxylin and eosin along with Giemsa for $H$. pylori and assessed by an expert pathologist for the presence of gastritis according to the updated Sydney classification $^{11}$. All children who had antrum biopsy were included in the study. Data collected retrospectively included age, gender and histologic findings using the patients EGD and pathology reports. Each pathology report contains histological description, Sydney classification and pathological diagnosis of tissue specimen. Patients were defined as $H$. pylori infected when histology was positive for $H$. pylori.

Ethical approval was obtained from ethical board of Ankara University.

\section{Statistical Analysis}

A chi-square test was used for categorical variables. Student $t$ test was used for normal continuous variables. All $\mathrm{p}$ values were two tailed and $>0.05$ considered nonsignificant. SPSS $16^{\circledR}$ was used for statistical analysis.

\section{Results}

Although no differences were observed considering age and gender between the groups, H.pylori positivity, gastritis and gastric mucosal atrophy were significantly different. The prevalence of $\mathrm{H}$.pylori was significantly higher in Group I (48.1\%) than Group II (23.1\%) (p $<0.001)$. Also in Group I, gastritis and gastric mucosal atrophy was significantly higher than Group II $(p<0.001)$. The demographic and histopathological data of the analyzed group I and II are shown in Table I.

In both Group I and II, H. pylori positive patients were older $(13.4 \pm 3.6$ years) than $H$. pylori negative counterparts $(11.8 \pm 5$ years $)$ $(\mathrm{p}<0.001)$. The prevalence of antral gastritis and gastric mucosal atrophy were significantly related with $\mathrm{H}$.pylori positivity $(\mathrm{p}<0.001)$ (Table II ) Exploring H. pylori positivity in age groups of five, we found that in Group I, rate of $H$. pylori positivity is statistically signiciant in each age group $(\mathrm{p}<0.05)$, while in Group II the difference is insignificant $(p>0.05)$ (Figure 1).

\section{Discussion}

Our single-center retrospective study showed that the current prevalence of H.pylori in 2013 is significantly lower compared to the prevalence of H.pylori in 2003. Decrease in the prevalence of $H$.pylori infection was reported in European countries like Finland, Denmark, Germany among others previously ${ }^{12,13}$. A study from Finland showed a decrease in serum $H$. pylori IgG positivity from 56 to 31 percent in adults ${ }^{5}$. Likewise the prevalence dropped from 21 to 10 percent in a Dutch study concerning children. Both studies were conducted between the 70's and the 90's. In the developing world, the trend was similar yet $H$. pylori prevalence was higher. In a large cohort of Brazilian children $H$. pylori was investigated by rapid urease test and postivity decreased from 60.4 to 30.4 percent in a decade from 1993 to

Table I. Patient Characteristics with Respect to Timing of Endoscopy.

\begin{tabular}{lccc}
\hline & $\begin{array}{c}\text { Group I } \\
(\mathrm{n}=131)\end{array}$ & $\begin{array}{c}\text { Group II } \\
(\mathrm{n}=249)\end{array}$ & $\mathrm{p}$ \\
\hline Age, years & $12.1 \pm 4$ & $12.4 \pm 5$ & 0.521 \\
Sex (Female), n (\%) & $89(67.9)$ & $164(65.9)$ & 0.386 \\
H. pylori positivity, n (\%) & $63(48.1)$ & $59(23.7)$ & $<0.001$ \\
Antral gastritis, n (\%) & $99(75.6)$ & $88(35.3)$ & $<0.001$ \\
Atrophy, n (\%) & $54(41.2)$ & $7(2.8)$ & $<0.001$ \\
\hline
\end{tabular}


Table II. Patient Characteristics with Respect to H. Pylori Presence.

\begin{tabular}{lccc}
\hline & $\begin{array}{c}\text { Children with } \\
\text { H. pylori }(+) \\
(\mathrm{n}=122)\end{array}$ & $\begin{array}{c}\text { Children with } \\
\text { H. pylori }(-)\end{array}$ & $\mathrm{p}$ \\
& $13.4 \pm 3.6$ & $11.8 \pm 5$ & $<0.01$ \\
\hline Age, years & $86(70.5)$ & $167(66)$ & 0.295 \\
Sex (Female), n (\%) & $114(93.4)$ & $73(28.3)$ & $<0.001$ \\
Antral gastritis, n (\%) & $42(34.4)$ & $19(7.4)$ & $<0.001$ \\
Atrophy, n (\%) & &
\end{tabular}

$2002{ }^{14}$. Two findings are striking in these studies; decreasing prevalence through time and lower prevalences in developed countries. The reasons of decline of $H$. pylori infection have not been fully clarified yet. In Finland, decrease of $H$. pylori infection is believed to be due to the "screen and treat" project ${ }^{15}$. In Czech Republic, decline in $H$. pylori prevalence is explained by the profound socio-economic changes after the fall of communist regimes ${ }^{16}$. Poor living standards, low socioeconomic status, overcrowded families and low education of parents are stil major risk factors of $H$. pylori infection. Considering risk factors, it is not surprising to see lower rates of infection where socioeconomic standards are higher. However, several studies from developing countries like Uganda, Brazil and Middle East region showed that the prevalence of $H$. pylori declined in children despite persisting poor hygiene, low standard of living and bitter socioeconomic conditions ${ }^{14}$.

Epidemiologic studies concerning change of H.pylori prevalence in Turkey is few. In the serology based study conducted with school children in Ankara, H. pylori prevalence was shown to decrease from $78.5 \%$ in 1990 to $66.3 \%$ in $2000^{9}$. Other cross sectional studies reported differing results. Latest pediatric studies revealed percentages between $23.6 \%$ and $50 \%$. Looking at the studies dating back to early 2000's, H. pylori prevalence in children was uniformly above $40 \%$, 17-21.

Explaining the decrement in H.pylori prevalence in our center is not easy. Relatively favourable and improving socioeconomic conditions may be the main reason. Gross domestic product per capita of Turkey almost tripled during the same period which may explain this trend 22 .
Prevalence studies of $H$. pylori is usually conducted by serology or urea breath test. These methods are noninvasive, easier to conduct and have a lower cost compared to EGD and histopathology. Urea breath test and H. pylori antigen in stool has high, sensitivity, accuracy and specificity evaluated against biopsy-based tests but $H$. pylori IgG in serum is not reliable for use in children ${ }^{10}$. Our data is based on histopathology which is the gold standart for H.pylori diagnosis. Morever, our findings confirmed the association of gastric mucosal atrophy and $H$. pylori infection as in previous studies ${ }^{23-25}$. We also observed an increased infection rate in older age groups. This was consistent with the literature where the rate of infection increases with age 26 . H. pylori positivity above 15 years was significantly lower in Group 2 compared to Group 1. This may be due to the tendency of H.pylori acquisition age increase in recent years.

Some weak points of the study need to be addressed. Nearly half of the pathology reports of antral biopsies in group 1 could not be reached due to archiving problems but as the reports were lost randomly, we think it is still not a biased sample. Site of biopsy was not standardized. Pathology specimens were evaluated by the same institution but by different professionals. Proton pump inhibitor and antibiotic usage before EGD could not be ruled out.

In conclusion, the prevelance of H.pylori infection in the children in our center has declined over the past 10 years. This decrease can be explained mostly by the relatively improving socio-economic status. However, it is necassary-also to consider the enviromental and human host factors. 


\section{REFERENCES}

1. Peleteriro B, Bastos A, Ferro A, Lunet N. Prevalence of Helicobacter pylori infection worldwide: A systematic review of studies with national coverage. Dig Dis Sci 2014; 59: 1698-1709.

2. Tadesse E, Daka D, Yemane D, Shimelis T. Seroprevalence of Helicobacter pylori infection and its related risk factors in symptomatic patients in southern Ethiopia. BMC Res Notes 2014; 7: 834.

3. Ozaydin N, Turkyilmaz SA, Cali S. Prevalence and risk factors of Helicobacter pylori in Turkey: A nationallyrepresentative, cross-sectional, screening with the ${ }^{13}$ C-Urea breath test. BMC Public Health 2013; 13: 1215.

4. Çınar A, Sadıç M, Atılgan Hİ, et al. Prevalence of Helicobacter pylori infection in school and pre-school aged children with C-14 urea breath test and the association with familial and environmental factors. Mol Imaging Radionucl Ther 2015; 24: 66-70.

5. Kosunen TU, Aromaa A, Knekt P, et al. Helicobacter antibodies in 1973 and 1994 in the adult population in Vammala, Finland. Epidemiol Infect 1997; 119: 29-34.

6. Roosendaal R, Kuipers EJ, Buitenwerf J, et al. Helicobacter pylori and the birth cohort effect: Evidence of a continuous decrease of infection rates in childhood. Am J Gastroenterol 1997; 92: 1480-1482.

7. Apostolopoulos P, Vafiadis-Zouboulis I, Tzivras M, Kourtessas D, Katsilambros N, Archimandritis A. Helicobacter pylori (H pylori) infection in Greece: The changing prevalence during a ten-year period and its antigenic profile. BMC Gastroenterol 2002; 2: 11.

8. Oona M, Utt M, Nilsson I, Uibo O, Vorobjova T, Maroos HI. Helicobacter pylori infection in children in Estonia: Decreasing seroprevalence during the 11-year period of profound socioeconomic changes. Helicobacter 2004; 9: 233-241.

9. Özden A, Bozdayı G, Özkan M, Köse KS. Changes in the seroepidemiological pattern of Helicobacter pylori infection over the last 10 years in Turkey. Turk J Gastroenterol 2004; 15: 156-158.

10. Koletzko S, Jones NL, Goodman KJ, et al. Evidence based guidelines from ESPGHAN and NASPGHAN for Helicobacter pylori infection in children. J Pediatr Gastroenterol Nutr 2011; 53: 230-243.

11. Dixon MF, Genta RM, Yardley JH, et al. Classification and grading of gastritis. The updated Sydney System. International Workshop on the Histopathology of Gastritis, Houston 1994. Am J Surg Pathol 1996; 20: 1161-1181.

12. Dahlerup S, Andersen RC, Nielsen BS, et al. Firsttime urea breath tests performed at home by 36,629 patients: A study of Helicobacter pylori prevalence in primary care. Helicobacter 2011; 16: 468-474.
13. Rothenbacher D, Schultze V, Jähnig P, Scharschmidt B, Brenner $\mathrm{H}$. Evidence of a rapid decrease in prevalence of Helicobacter pylori infection in children of a high risk group living in Germany. Eur J Pediatr 2004; 163: 339-340.

14. Kawakami E, Machado RS, Ogata SK, Langner M. Decrease in prevalence of helicobacter pylori infeciton during a 10-year period in Brazilian children. Arq Gastroenterol 2008; 45: 147-151.

15. Salomaa-Rasanen A, Kosunen TU, Aromaa AR, Knekt P, Sarna S. A "screen-and-treat" approach for Helicobacter pylori infection: A population-based-study in Vammala, Finland. Helicobacter 2010; 15: 28-37.

16. Bures J, Kopacova M, Koupil I, et al. Significant decrease in prevalence of Helicobacter pylori in the Czech Republic.World J Gastroenterol 2012; 18: 44124418.

17. Ceylan A, Kirimi E, Tuncer O, Türkdoğan K, Ariyuca S, Ceylan N. Prevalence of Helicobacter pylori in children and their family members in a district in Turkey. J Health Popul Nutr 2007; 25: 422-427.

18. Süoglu OD, Gökçe S, Saglam AT, Sökücü S, Saner G. Association of Helicobacter pylori infection with gastroduodenal disease, epidemiologic factors and iron-deficiency anemia in Turkish children undergoing endoscopy, and impact on growth. Pediatr Int 2007; 49: 858-863.

19. Sökücü S, Süoğlu OD, Türkkan E, Elkabes B, Ozden T, Saner G. Helicobacter pylori infection in Turkish children with gastrointestinal symptoms and evaluation of serology. Turk J Pediatr 2002; 44: 102-108.

20. Yilmaz E, Doğan Y, Gürgöze MK, Unal S. Seroprevalence of Helicobacter pylori infection among children and their parents in eastern Turkey. J Paediatr Child Health 2002; 38: 183-186.

21. Selimoglu MA, Ertekin V, Inandi T. Seroepidemiology of Helicobacter pylori infection in children living in eastern Turkey. Pediatr Int 2002; 44: 666-669.

22. "TÜİK Gösterge.” TÜİK Gösterge. < https://biruni.tuik. gov.tr/gosterge/?locale $=\operatorname{tr}>$. Accessed March, 2017.

23. Guarner J, Herrera-Goepfert R, Mohar A, et al. Gastric atrophy and extent of intestinal metaplasia in a cohort of Helicobacter pylori infected patients. Hum Pathol 2001; 32: 31-35.

24. Kato S, Nakajima S, Nishino Y, et al. Association between gastric atrophy and Helicobacter pylori infection in Japanese children: A retrospective multicenter study. Dig Dis Sci 2006; 51: 99-104.

25. Villarreal-Calderon R, Luévano-González A, AragónFlores M, et al. Antral atrophy, intestinal metaplasia, and preneoplastic markers in Mexican children with Helicobacter pylori-positive and Helicobacter pylorinegative gastritis. Ann Diagn Pathol 2014; 18: 129-135.

26. Hasosah M, Satti M, Shehzad A, et al. Prevalence and risk factors of Helicobacter pylori infection in Saudi children: a three-year prospective controlled study. Helicobacter 2015; 20: 56-63. 